\title{
Cyclic constitutive model for concrete
}

\author{
José Fernando Sima*, Pere Roca, Climent Molins \\ Department of Construction Engineering, Technical University of Catalonia, Barcelona, Spain
}

Received 2 May 2006; received in revised form 8 May 2007; accepted 10 May 2007

\begin{abstract}
A constitutive model for concrete subjected to cyclic loadings in both compression and tension is presented. The proposed model is intended to provide improvements on modelling the cyclic behaviour of concrete structures in the context of computational programs based on a smeared crack approach. Particular emphasis has been paid to the description of the strength and stiffness degradation produced by the load cycling in both tension and compression, the shape of unloading and reloading curves and the transition between opening and closing of cracks. Two independent damage parameters in compression and in tension have been introduced to model the concrete degradation due to increasing loads. In the case of cyclic compressive loading, the model has been derived from experimental results obtained by other authors by considering the dependency of the cyclic variables with the damage level attained by the concrete. In the case of cyclic tension a simple model is adopted based on experimental observations. The main novelty of the proposed constitutive model lays in the fact that all the required input data can be obtained through the conventional monotonic compression and tension tests.
\end{abstract}

(C) 2007 Published by Elsevier Ltd

Keywords: Reinforced concrete; Constitutive model; Cyclic load; Damage; Cracking

\footnotetext{
* Corresponding author. Tel.: +34 934017380; fax: +34 934054135 .

E-mail address: jose.fernando.sima@upc.edu (J.F. Sima).
}

damage theory have been recently developed. Although it has been proved that the models derived from theory of plasticity and continuum damage theory can accurately simulate the observed behaviour of concrete, its application in the engineering practice is reduced. This is motivated by the great amount of parameters that are usually needed and the difficulty to obtain them through conventional laboratory tests. In the context of this study, only simplified models which are essentially mathematical formulations derived from the generalization of test results for concrete under various loading histories are treated. Many of these models have been documented in the literature, like Sinha et al. [1], Karsan and Jirsa [3], Yankelevsky and Reinhardt [4], Mander, Priestley and Park [5], Bahn and Hsu [6], Chang and Mander [7], Mansour and Hsu [8], Palermo and Vecchio [9] among others. Most of them refer only to the compressive cyclic behaviour of concrete and only a few consider the cyclic tension response.

Sinha et al. [1] carried out an experimental investigation on the behaviour of plain concrete under cyclic compression loading. A series of forty-eight tests were performed on concrete cylinders to obtain information about the properties of the envelope curve and the unloading and reloading curves, and analytical stress-strain relations for cyclic loading were 


\section{Notation}

$\varepsilon_{0} \quad$ Strain at the elastic limit in compression.

$\varepsilon_{c}^{\prime} \quad$ Strain at peak of the stress-strain curve in compression.

$\varepsilon_{\mathrm{op}} \quad$ Strain at the optional point of the softening branch in compression.

$\varepsilon_{\mathrm{ct}}$ Tensile strain corresponding to the tensile strength.

$\varepsilon_{\text {un }} \quad$ Unloading strain on envelope curve for concrete in compression.

$\varepsilon_{\mathrm{re}} \quad$ Reloading strain on envelope curve after a complete cycle in compression.

$\varepsilon_{\mathrm{pl}} \quad$ Residual plastic strain after the unloading curve in compression.

$\varepsilon_{\text {re }}^{\prime} \quad$ Reloading strain on envelope curve after an incomplete cycle in compression.

$\varepsilon_{\text {rev }} \quad$ Strain at the reversal point for the case of partial unloading-reloading in compression.

$\varepsilon_{\text {un }}^{n=1,2}$ Strain at the reversal point for the case of unloading-partial reloading in compression.

$\delta^{-} \quad$ Damage in compression.

$\delta^{+} \quad$ Damage in tension.

$\delta_{\text {un }} \quad$ Damage at the unloading strain on envelope curve for concrete in compression.

$\delta_{\text {re }} \quad$ Damage at the reloading strain on envelope curve for concrete in compression.

$\delta_{\text {rev }} \quad$ Damage at the reversal point of the unloading curve.

$E_{0} \quad$ Initial modulus of concrete.

$E_{\mathrm{pl}} \quad$ Stiffness at zero stress after unloading.

$E_{\mathrm{re}} \quad$ Reloading stiffness in compression.

$E_{\mathrm{pl}}^{1} \quad$ Stiffness at zero stress for the case of unloadingpartial reloading-unloading in compression.

$E_{\text {new }} \quad$ Unloading-reloading stiffness in tension.

$f_{0} \quad$ Stress at the elastic limit in compression.

$f_{c}^{\prime} \quad$ Compressive strength of concrete.

$f_{\text {op }} \quad$ Stress at the optional point of the softening branch in compression.

$f_{\text {un }}^{n=1,2}$ Stress at the reversal point for the case of unloading-partial reloading in compression.

$f_{\text {ct }} \quad$ Tensile strength of concrete.

$G_{f} \quad$ Fracture energy of the concrete in tension.

$l^{*} \quad$ Characteristic length or crack bandwidth.

$\sigma_{f} \quad$ Crack closure stress.

$\sigma_{f}^{0} \quad$ Initial crack closure stress.

derived. They assumed the property of uniqueness of the stress-strain relations (i.e. if the envelope, the unloading and the reloading curve passing through any point in the stress-strain plane remain independent of the previous load history, then the stress-strain relationship is unique) to predict behaviour of concrete subjected to an arbitrary compression load history. This hypothesis was refuted by subsequent experimental evidence.
Karsan and Jirsa [3] developed an experimental study of the strength and behaviour of plain concrete subjected to repetitions of compressive stress to multiple levels. A total of 46 short rectangular columns were tested under cyclically varying axial loads. This was carried out in order to determine the stress-strain envelope and the unloading and reloading curves. The test results indicated that the stress-strain paths under cyclic loading generally do not exceed the envelope curve; furthermore, this curve can be modeled as the stress-strain curve obtained under monotonic loading to failure. The authors reported that the loading and unloading curves starting from a point within the stress-strain domain were not unique and that the value of stress and strain at the peak of the previous loading cycle had to be known to estimate the response. They considered the residual plastic strain as principal parameter to determine the unloading curve equation and proposed an empirical formula to correlates the residual plastic strain with the point on the envelope from which unloading starts.

When reloading starts from zero stress to meet the envelope curve, it is found that the reloading curve becomes rather flat in most of its range and may be represented by a simple straight line (Sinha et al. [1]) or a second-order parabola (Karsan and Jirsa [3]).

Yankelevsky and Reinhardt [4] proposed a simple uniaxial stress-strain model, based on geometrical properties of the loading history curves in the uniaxial stress-strain plane. They modeled the complete unloading-reloading cycle by a set of pieced linear curves defined by a set of six geometrical loci (called focal points) in the stress-strain plane.

Mander, Priestley and Park [5] developed a stress-strain model for concrete subjected to uniaxial reversed compressive loading with incursions in tension and confined by transverse reinforcement. They used a modified expression of the equation suggested by Popovics [10] for monotonic compression loading. The unloading curve was derived by the parameter adjustment, based on selected experimental unloading curves for confined and unconfined concrete. For the reloading curve, a linear stress-strain relation is assumed between the point of zero stress and the unloading strain, while a parabolic transition curve is adopted between the unloading strain and the return to the monotonic stress-strain. Martinez-Rueda and Elnashai [11] modified this model to include the effect of degradation in stiffness and strength due to cyclic loading.

Chang and Mander [7] proposed an advanced model to simulate the hysteretic behaviour of confined and unconfined concrete in both cyclic compression and tension for both ordinary as well as high strength concrete including for the first time, effects of degradation produced by partial looping and a crack-closing model. The equation used by the authors for the unloading and reloading curves was a general Ramberg-Osgood equation [12] adjusted by a series of parameters: the slope at the origin and the slope at the end of each curve. The complete behaviour of concrete under cyclic loading was defined through a series of rules for each kind of curve (envelopes curves, unloading curves and reloading curves). To define the cyclic properties of concrete in compression, statistical regression analysis was performed on 
the experimental data from Sinha et al. [1], Karsan and Jirsa [3], Spooner and Dougill [13], Okamoto et al. [14] and Tanigawa et al. [15]. The same expressions proposed by the authors for compression were used for the tension cyclic response.

Bahn and Hsu [6] developed a parametric study and an experimental investigation on the behaviour of concrete under random cyclic compressive loading. They studied in a semiempirical way a set of parameters that control the overall shape of cyclic stress-strain curve. This was carried out by combining the theoretical simulation and a series of experimental results. A power type equation was proposed for the unloading curve and a linear relationship for the reloading curve.

A constitutive model for concrete consistent with a compression field approach (Modified Compression Field Theory, Vecchio and Collins [16]) was proposed by Palermo and Vecchio [9]. The concrete cyclic model presented by the authors considers concrete in both compression and tension. The unloading and reloading curves are linked to the envelope curves, which are represented by the monotonic response curves. Unloading is modelled using a Ramberg-Osgood formulation, considering boundary conditions at the onset of unloading and at a zero stress. Reloading is modelled as a linear curve with degrading reloading stiffness. This model also considers the case of partial unloading-reloading and a linear crack-closing function. All the model parameters were statistically derived from tests developed by others authors.

An extension of the Softened Membrane Model (Hsu and Zhu [17]) subjected to reversal cyclic shear stresses, has been presented by Mansour and Hsu [8]. This work includes a cyclic uniaxial constitutive relationship for concrete that takes into account a "softening" of the concrete compressive strength caused by a constant tensile strain in the orthogonal direction. The unloading and reloading curves were formed by a set of pieced linear curves.

More recently, Sakai and Kawashima [18] proposed an unloading and reloading model for concrete confined by transverse reinforcement. This model is based on tests results on reinforced concrete column specimens. It considers the effect of repeated unloading/reloading cycles and partial unloading-reloading by taking into account the number of cycles.

Under real cyclic or dynamic actions, concrete may experience complex loading processes involving not only full unloading-reloading cycles in compression or tension, but also partial unloading and reloading processes and mixed cycles involving compression and tension stresses and cracking. Some of the models available focus on particular aspects of the cyclic behaviour. Thus, Karsan and Jirsa [3], Yankelevsky and Reinhardt [4], Mander, Priestley and Park [5] or Bahn and Hsu [6] are oriented to the compressive regime. Moreover, Karsan and Jirsa [3], Yankelevsky and Reinhardt [4], Mander, Priestley and Park [5] deal with only total unloading and reloading processes. The principal shortcomings of other models is the unusual set of parameters required for their entire definition, such is the case of many models based on the theory of plasticity or the theory of damage (CEB [2]). Two of the previously referred to cyclic models have been considered in the first stage of the investigation, which present a complete modellization of the concrete behavior under general cyclic loads: Chang and Mander [8] and Palermo and Vecchio [10]. Although both formulations have shown good results, they present some characteristics which may be improved. Most of them are referred to the modellization of unloading and reloading curves in compression (see Section 2.2).

In this paper, a constitutive model for the description of the response of concrete under general cyclic loading is presented. Compared to previous ones, the model presents several advantages. It affords to consider all the hysteretic characteristics of the complex behaviour of concrete in a simple and practical way. It can be used to simulate the cyclic response of concrete subject to general load conditions, including partial unloading or reloading or mixed hysteretic loops involving the transition from compression to tension stresses or vice-versa. Moreover, all the required input data can be obtained through conventional laboratory monotonic compression and tension tests. This is an important issue which determines the applicability of the present model in engineering practice. The model has been validated by comparison with available experimental results provided by different authors (see Section 5).

As an ongoing development, the model presented here has been implemented in a numerical formulation suitable for the analysis of framed reinforced concrete structures based on the Generalized Matrix Formulation (Molins and Roca [19]). The results obtained through the use of the model for the nonlinear analysis of spatial reinforced concrete frames and complex structures will be presented in a future paper.

\section{Proposed model for concrete in cyclic compression}

\subsection{Envelope curve}

It is commonly accepted by most researchers (Karsan and Jirsa [3]; Yankelevsky and Reinhardt [4], Bahn and Hsu [6], among others) that the envelope curve for a concrete subjected to axial cyclic compression can be approximated by the monotonic stress-strain curve. In turn, the monotonic curve adopted as envelope should verify some desirable characteristics: (1) the slope at the origin should be equal to the initial modulus of deformation, (2) it should describe correctly the ascending and the descending post peak (softening) branch and (3) it should permit us to adjust the post peak behaviour to experimental results.

The properties of the monotonic stress-strain curve of concrete have been studied by many researchers. Some classical references on this topic are Hognestand et al. [20], Popovics [10] or Tsai [21]. A more extensive list of contributions can be found in Chang and Mander [7].

Experimental results have shown that the monotonic compression curve of concrete presents a linear response until approximately a half of the compressive strength. Due to that, a first linear relation is considered herein until the elastic limit 
is reached. An exponential type equation is considered for the envelope stress-strain curve of concrete beyond the elastic limit. It has been observed that such exponential equation fits well the experimental results. This curve is defined by a set of parameters that can be obtained in a monotonic compression test, including (1) the initial modulus of concrete $E_{0}$, (2) the strain at the elastic limit $\varepsilon_{0}$ and (3) the coordinates at the peak of the stress-strain curve $\left(\varepsilon_{c}^{\prime}, f_{c}^{\prime}\right)$.

The following equation is adopted for the stress-strain envelope curve of concrete:

$\begin{cases}\sigma=\varepsilon E_{0} & \varepsilon \leq \varepsilon_{0} \\ \sigma=\left[\varepsilon_{0}(1-A)+A \varepsilon \mathrm{e}^{\left(\frac{\varepsilon_{0}-\varepsilon}{\varepsilon_{c}^{\prime}}\right)}\right] E_{0} \quad \varepsilon>\varepsilon_{0}\end{cases}$

where

$A=\frac{f_{c}^{\prime}-\varepsilon_{0} E_{0}}{E_{0}\left(\varepsilon_{c}^{\prime} \mathrm{e}^{\frac{\varepsilon_{0}}{\varepsilon_{c}^{\prime}}-1}-\varepsilon_{0}\right)}$.

This equation is a special case of the equation proposed by Mazars and Pijaudier-Cabot [22] for a damage model for concrete and is used by many authors for concrete models (Faría et al. [23], Saetta et al. [24] among others) and later extended to masonry models (Saetta et al. [25]; Berto et al. [26]). The original parameters have been rewritten in terms of the set of parameters obtained in a 1D monotonic compressive test (as is previously mentioned).

Eq. (1) can be rewritten as

$\sigma=\left(1-\delta^{-}\right) E_{0} \varepsilon$

where

$\delta^{-}=\left[1-\frac{\varepsilon_{0}}{\varepsilon}(1-A)-A \mathrm{e}^{\left(\frac{\varepsilon_{0}-\varepsilon}{\varepsilon_{c}^{\prime}}\right)}\right]$.

The compression damage parameter $\delta^{-}$represents the material degradation in compression and varies from 0 (material without deterioration) to 1 (completely damaged material).

Even when this curve presents a good agreement with typical monotonic stress-strain curves of concrete, it does not allow the adjustment of the softening branch to experimental results. Carrying out this adjustment is very important in some cases like in confined concrete modelling. Because of that, the possibility to optionally including a new point $\left(\varepsilon_{\mathrm{op}}, f_{\mathrm{op}}\right)$ to define the descending branch as a new variable is considered (Fig. 1). A new descending branch is proposed herein, which has been obtained by adjusting an exponential curve to zero slope at the peak stress point and to the new point $\left(\varepsilon_{\mathrm{op}}, f_{\mathrm{op}}\right)$. This equation can be written as follows:

$\sigma=\left[B+C \varepsilon \mathrm{e}^{\left(\frac{\varepsilon_{0}-\varepsilon}{\varepsilon_{0}^{\prime}}\right)}\right] E_{0} \quad \varepsilon>\varepsilon_{c}^{\prime}$

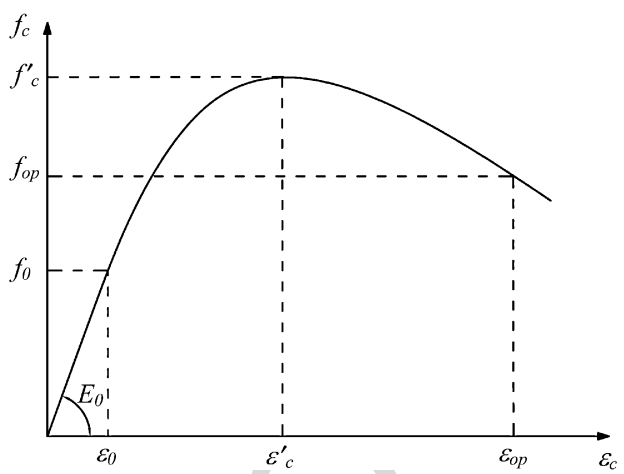

Fig. 1. Envelope curve of concrete.

where

$$
\begin{aligned}
& B=\frac{f_{\mathrm{op}} \varepsilon_{c}^{\prime} \mathrm{e}^{\left(\frac{\varepsilon_{0}}{\varepsilon_{c}^{\prime}}-1\right)}-\varepsilon_{\mathrm{op}} f_{c}^{\prime} \mathrm{e}^{\frac{\varepsilon_{0}}{\varepsilon_{c}^{\prime}}\left(1-\frac{\varepsilon_{u}}{\varepsilon_{0}}\right)}}{E_{0}\left[\varepsilon_{c}^{\prime} \mathrm{e}^{\left(\frac{\varepsilon_{0}}{\varepsilon_{c}^{\prime}}-1\right)}-\varepsilon_{\mathrm{op}} \mathrm{e}^{\frac{\varepsilon_{0}}{\varepsilon_{c}^{\prime}}\left(1-\frac{\varepsilon_{u}}{\varepsilon_{0}}\right)}\right]} \\
& \text { and } \\
& C=\frac{f_{c}^{\prime}-f_{\mathrm{op}}}{E_{0}\left[\varepsilon_{c}^{\prime} \mathrm{e}^{\left(\frac{\varepsilon_{0}}{\varepsilon_{c}^{\prime}}-1\right)}-\varepsilon_{\mathrm{op}} \mathrm{e}^{\frac{\varepsilon_{0}^{\prime}}{\varepsilon_{c}^{\prime}}\left(1-\frac{\varepsilon_{u}}{\varepsilon_{0}}\right)}\right]} .
\end{aligned}
$$

The Eq. (5) can be rewritten in terms of the compressive damage as follows:

$\sigma=\left(1-\delta^{-}\right) E_{0} \varepsilon$

where

$\delta^{-}=\left[1-\frac{B}{\varepsilon}-C \mathrm{e}^{\left(\frac{\varepsilon_{0}-\varepsilon}{\varepsilon_{c}^{\prime}}\right)}\right] \varepsilon>\varepsilon_{c}^{\prime}$.

\subsection{Unloading and reloading curves}

As it has been observed by many researchers (Sinha et al. [1], Karsan and Jirsa [3], Bahn and Hsu [6]), when a concrete specimen is monotonically loaded up to a certain strain level and then unloaded to a zero stress level in a typical cyclic test, the unloading curve is concave from the unloading point and characterized by high stiffness at the beginning (Fig. 2). The stiffness gradually decreases and becomes very flat at low stress levels and the residual plastic strains are considerably reduced. When reloading is performed from zero stress up to the envelope curve, it has been observed that the curve is rather flat in almost all of its length. Depending on the compression damage level, a great amount of energy may be dissipated in a complete cycle. The aim of modeling the shape of the unloading and reloading curves is to capture the damage accumulation and the energy dissipation of the material due to cyclic loading.

The shape of the unloading and reloading curves depends on the amount of non recoverable damage in the concrete. Many models consider the unloading strain as the parameter that 


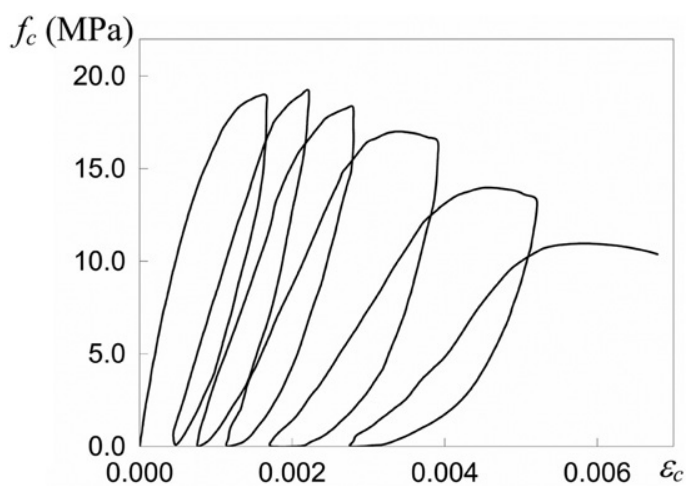

Fig. 2. Typical cyclic compression test from Karsan and Jirsa (1969).

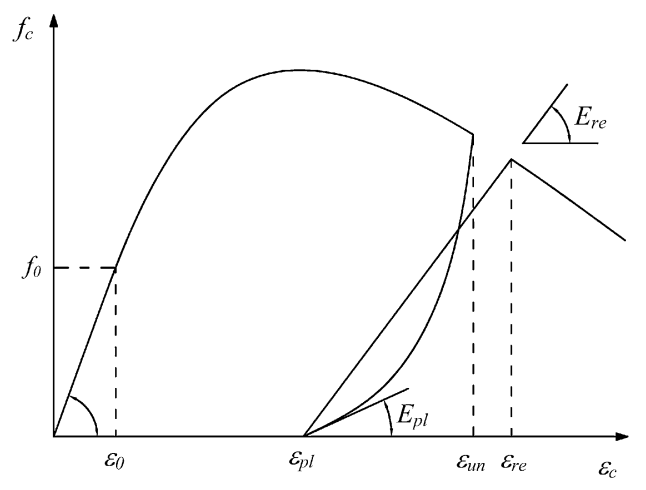

Fig. 3. Complete unloading-reloading cycle in compression.

defines the unloading and reloading path and determines the degree of damage caused by the cycling (Karsan and Jirsa [3], or Palermo and Vecchio [9]). Several types of curves have been used to reproduce the unloading curve also, like the Ramberg-Osgood equation used by Palermo and Vecchio [9] or Chang and Mander [7], the power type used by Bahn and Hsu [6] or the multilinear curve proposed by Yankelevsky and Reinhardt [4] or Mansour and Hsu [8]. In turn, reloading can be accurately modelled by a linear curve as is done by most researchers (Palermo and Vecchio [9], Bahn and Hsu [6], among others). Herein, an exponential type equation is proposed for the unloading curve of concrete and a linear type equation is used for the reloading curve (Fig. 3). The equation proposed for the unloading branch includes the mean features of the unloading curves obtained experimentally, such as the curvature of the unloading curve, the initial unloading stiffness, the final unloading stiffness and the unloading strain-plastic strain ratio. It has been observed that these characteristics vary with the accumulation of damage. Some previous works ignore this fact and consider as constants one or more characteristics. Chang and Mander [7] consider the initial unloading stiffness equal to the initial modulus of deformation of the concrete. Palermo and Vecchio [9] assigned to the initial unloading stiffness a value equal to the initial tangent stiffness of the concrete and a value equal to the $7.1 \%$ of the initial tangent stiffness of the concrete to the final unloading stiffness. Herein, none of these important characteristics are previously fixed. The final unloading stiffness and the unloading strain-plastic strain ratio are explicitly related to the damage accumulation in

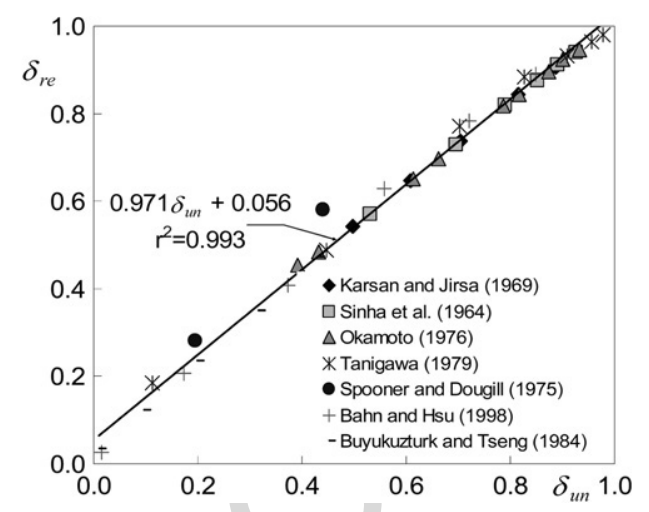

Fig. 4. Relationship between the reloading damage and the unloading damage obtained by means of statistical regression on selected experimental results.

the concrete. As a consequence, the curvature of the unloading curve and the initial unloading stiffness are implicitly related to the damage accumulation.

The proposed unloading curve is given by the equation:

$\sigma=D^{1} \mathrm{e}^{D^{2}\left(1-\frac{\varepsilon-\varepsilon_{\mathrm{pl}}}{\varepsilon_{\text {un }}-\varepsilon_{\mathrm{pl}}}\right)} E_{0}\left(\varepsilon-\varepsilon_{\mathrm{pl}}\right)$

where

$D^{1}=\frac{r\left(1-\delta_{\mathrm{un}}\right)}{(r-1)} \quad D^{2}=\operatorname{Ln}\left[\frac{R\left(1-\delta_{\mathrm{un}}\right)(r-1)}{r}\right]$

with $r=\varepsilon_{\mathrm{un}} / \varepsilon_{\mathrm{pl}}$ and $R=E_{\mathrm{pl}} / E_{0} . \varepsilon_{\mathrm{pl}}$ is the strain at zero stress, $E_{\mathrm{pl}}$ is the stiffness at the end of the unloading curve and (Fig. 3), $\delta_{\text {un }}$ is the compressive damage $\delta^{-}$at the unloading point which is the only parameter used here to define the complete unloading-reloading path. The dependence of the other variables with this parameter has been determined in a semi empirical way. A series of cyclic test on plain concrete under compressive loadings have been reproduced with this model and statistical regression has been performed as is later shown. The test considered are those performed by Sinha et al. [1], Karsan and Jirsa [3], Spooner and Dougill [13], Okamoto et al. [14], Tanigawa et al. [15], Buyukozturk and Tseng [27] and Bahn and Hsu [6].

The reloading response is modelled by a linear curve as is done by most researchers (Palermo and Vecchio [9], Bahn and Hsu [6], Sakai and Kawashima [18] among others). This approach is in agreement with experimental results.

A meaningful feature included in the model, which is not always considered by other authors, is the degradation in reloading stiffness with load cycling. As has been observed in test results, the reloading curve does not return to the envelope curve at the previous maximum unloading strain and further straining is needed to take up again the envelope curve. It has been found that the relationship between the reloading compressive damage $\delta_{\text {re }}$ (defined as the compressive damage $\delta^{-}$at the reloading strain $\varepsilon_{\mathrm{re}}$ ) and the unloading compressive damage $\delta_{\text {un }}$ presents a linear behavior (Fig. 4). The difference between $\delta_{\text {un }}$ and $\delta_{\text {re }}$ describes the damage accumulated in each cycle. The effect of cyclic stiffness degradation and its dependence with the unloading compressive damage can be observed in Fig. 5. It can be noted that the unloading 


\section{ARTICTE E IN PRESS}

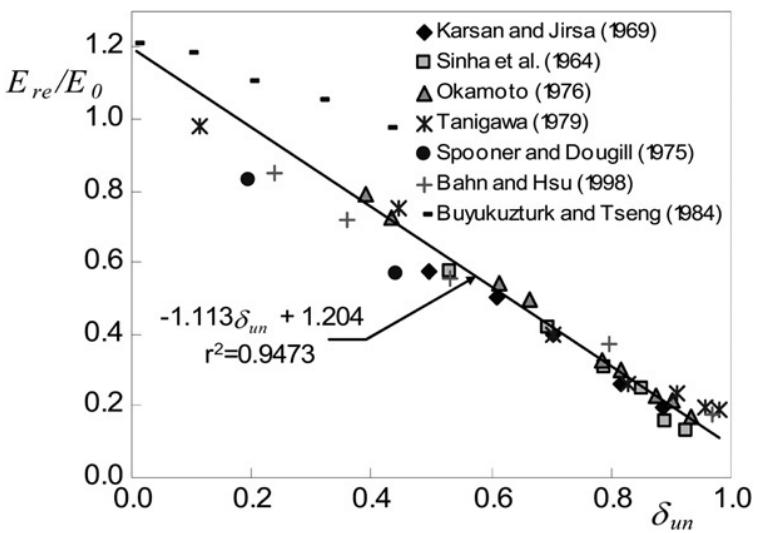

Fig. 5. Relationship between the reloading stiffness and the unloading damage obtained by statistical regression on selected experimental results.

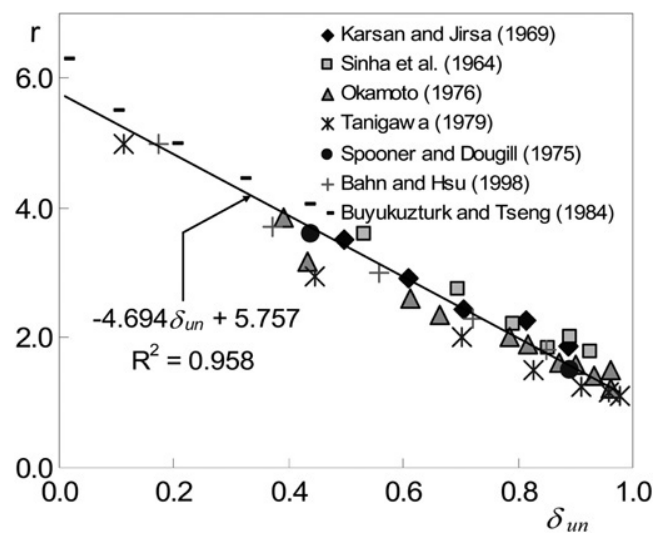

Fig. 6. Relationship between the unloading strain-plastic strain ratio and the unloading damage obtained by means of statistical regression on selected experimental results.

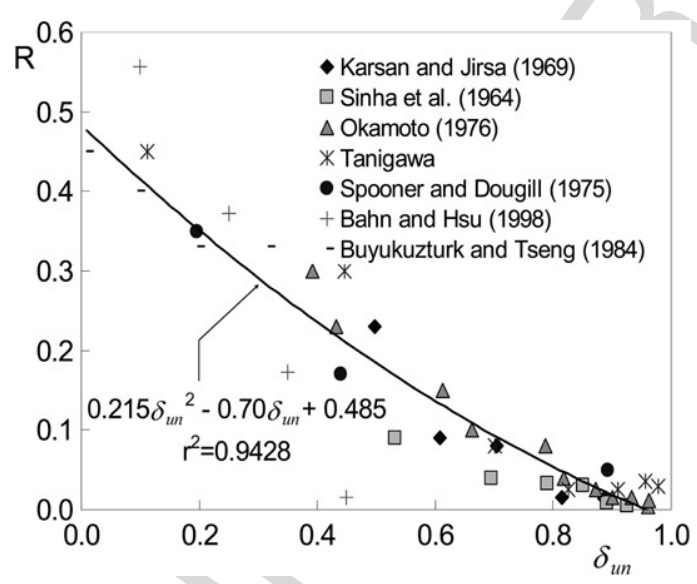

Fig. 7. Relationship between the final unloading stiffness-initial unloading stiffness ratio and the unloading damage obtained by means of statistical regression on selected experimental results.

strain-plastic strain ratio presents a linear dependence with the unloading compressive damage (Fig. 6). Increasing in the unloading compressive damage produces a decrease in the final unloading stiffness. This relationship can be adequately modelled also by a second order parabola (Fig. 7).

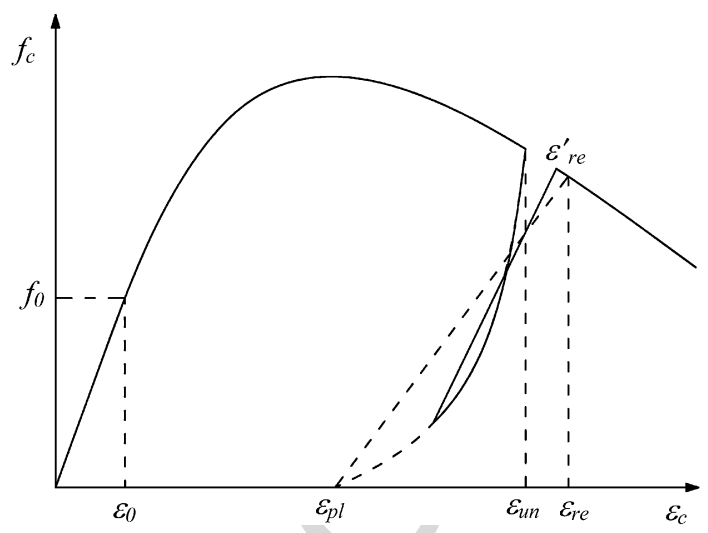

Fig. 8. Reloading from partial unloading in compression.

A linear variation between the unloading damage $\delta_{\text {un }}$ and the reloading damage $\delta_{\text {re }}$ has been considered for the compressive damage $\delta^{-}$during the unloading path. For the reloading path, the compressive damage has been maintained as a constant, which is in agreement with experimental data (i.e. the test results suggest that the reloading curve becomes nonlinear only beyond the point of intersection with the unloading curves, often referred to as the common point). These relationships can be expressed as follows:

$\delta^{-}=\delta_{\text {un }}+\frac{\delta_{\text {re }}-\delta_{\text {un }}}{\varepsilon_{\mathrm{pl}}-\varepsilon_{\text {un }}}\left(\varepsilon-\varepsilon_{\text {un }}\right)$

for the unloading path, and

$\delta^{-}=\delta_{\mathrm{re}}$

for the reloading path.

\subsection{Partial unloading and reloading}

Most of the models available in the literature do not consider the behavior of concrete in the case of partial unloading and partial reloading. In other cases, this issue has been considered in a simplified way. There exists a lack of experimental information considering the general case of partial unloading followed by partial reloading. The curves proposed herein for the general case of partial unloading-reloading cycles are based on the test results by Bahn and Hsu [6], who developed a series of tests in order to study the response of concrete under random load cycles.

As is suggested by these experimental results, when a partial unloading occurs followed by reloading to meet the envelope curve, the reloading path can be modelled by the linear relationship connecting the reversal point with the point in the envelope curve that corresponds to a damage defined by Eq. (12) for the reversal point $\left(\varepsilon_{\text {rev }}^{\prime}\right)$

$\delta_{\mathrm{rev}}=\delta_{\mathrm{un}}+\frac{\delta_{\mathrm{re}}-\delta_{\mathrm{un}}}{\varepsilon_{\mathrm{pl}}-\varepsilon_{\mathrm{un}}}\left(\varepsilon_{\mathrm{rev}}-\varepsilon_{\mathrm{un}}\right)$

where $\varepsilon_{\text {rev }}$ is the strain at the reversal point (Fig. 8). The compressive damage remains equal to $\delta_{\text {rev }}$ during the reloading path. 


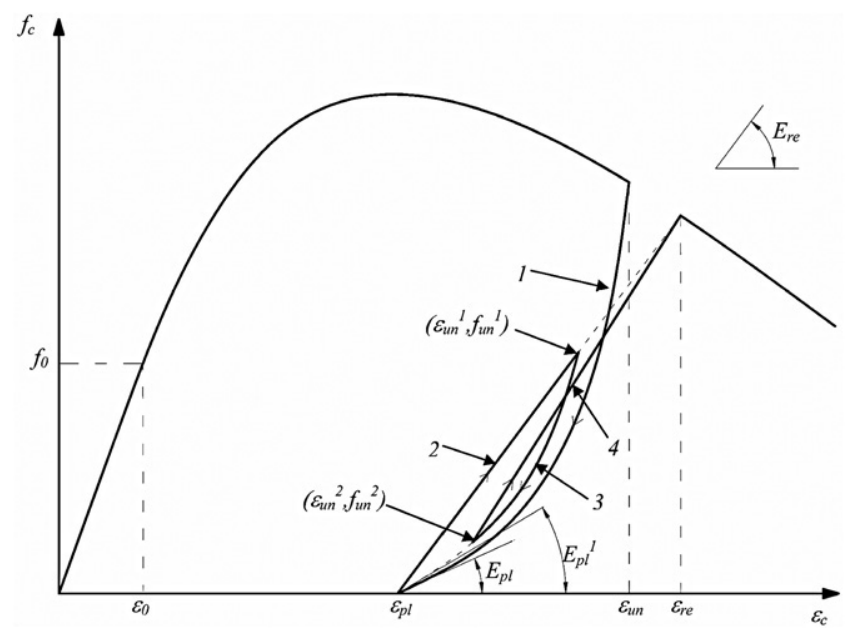

Fig. 9. Partial reloading followed by partial unloading for concrete in compression.

When a partial reloading is performed, the following unloading path is modeled by Eq. (10) but substituting the unloading strain and the slope at zero stress as follows (curve 3 in Fig. 9):

$\sigma=B^{1} \mathrm{e}^{A^{1}\left(1-\frac{\varepsilon-\varepsilon_{\mathrm{pl}}}{\varepsilon_{\mathrm{un}}^{1}-\varepsilon_{\mathrm{pl}}}\right)} E_{0}\left(\varepsilon-\varepsilon_{\mathrm{pl}}\right)$

where

$A^{1}=\operatorname{Ln}\left[\frac{R^{1}}{B^{1}}\right] \quad B^{1}=\frac{f_{\mathrm{un}}^{1}}{E_{0} \varepsilon_{\mathrm{un}}^{1}\left(1-r^{1}\right)}$

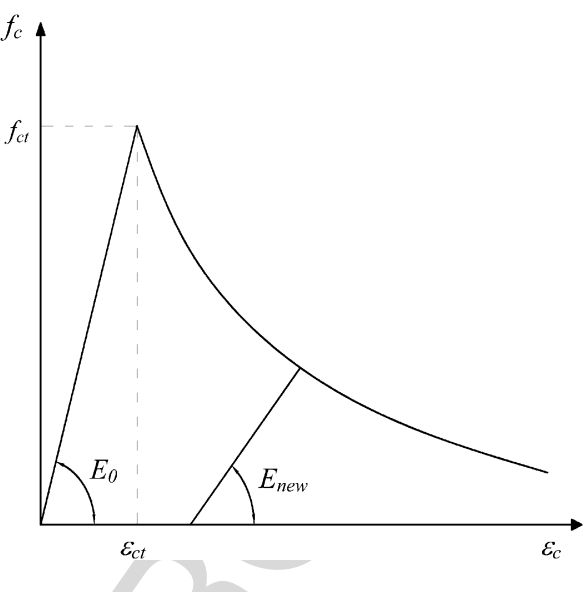

Fig. 10. Tension envelope curve for concrete. curves (Lin and Scordelis [31]) or combinations of them (Cornelissen et al. [32]).

The response of concrete under cyclic tension has been studied in detail by Reinhardt [33] and Reinhardt et al. [34]. More than 100 tests were performed on plain concrete under cyclic tension and numerical expressions for the softening branch and the unloading and reloading curves were derived. It was observed (like in the case of plain concrete under cyclic compression loadings) that the reloading curve does not return to the envelope curve at the previous maximum unloading strain and further straining is needed to taking up again the envelope curve. This phenomenon is less important than in compression. The energy dissipated in a tension cycle without incursions in the compression zone can be neglected when it is compared with the energy dissipated in a complete compression cycle. However, some authors (Okamura and Maekawa [35], Hordijk [36] or Palermo and Vecchio [9]) have provided an accurate approximation of the complete unloading-reloading cycle in tension.

The tension envelope curve adopted for the present formulation consists of a linear elastic relation until reaching the tensile strength, followed by an exponential curve to represent the softening branch

$\sigma=E_{0} \varepsilon_{\mathrm{ct}} \mathrm{e}^{\alpha\left(1-\frac{\varepsilon}{\varepsilon_{\mathrm{ct}}}\right)}$

where $\varepsilon_{\mathrm{ct}}$ is the tensile strain that corresponds with the tensile strength (Fig. 10) and $\alpha$ is defined by the following expression:

$\alpha=\left(\frac{G_{f} E_{0}}{l^{*} f_{\mathrm{ct}}^{2}}-\frac{1}{2}\right)^{-1} \geq 0$

where $G_{f}$ is the fracture energy (considered as a material property), $f_{\text {ct }}$ is the tensile strength of concrete and $l^{*}$ is a "characteristic length" or "crack bandwidth" introduced to guarantee the objectivity of the results with respect to the size of the finite element mesh (Oliver [37]).

Like in compression, it is useful to rewrite the expression (13) to define the damage in tension as:

$\sigma=\left(1-\delta^{+}\right) E_{0} \varepsilon$ 


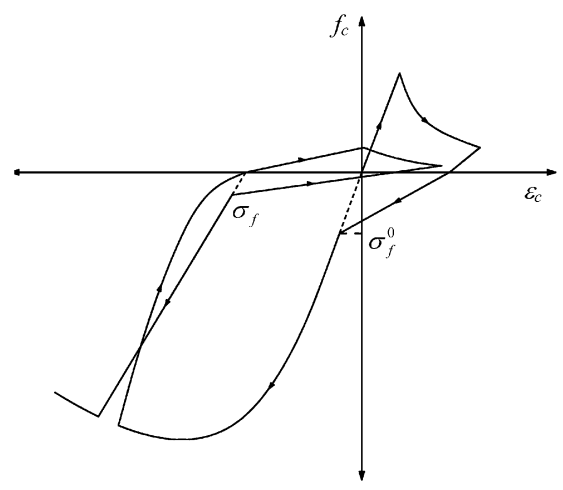

Fig. 11. Clack-closing model.

where

$\delta^{+}=1-\frac{\varepsilon_{\mathrm{ct}}}{\varepsilon} \cdot \mathrm{e}^{\alpha\left(1-\frac{\varepsilon}{\varepsilon_{\mathrm{ct}}}\right)}$.

The tensile damage parameter $\delta^{+}$measures the material degradation in tension and varies from 0 (material without deterioration) to 1 (completely damaged material).

In reinforced concrete, the tension stiffening effect can be modeled through an adequate adjustment of the fracture energy in (14).

Cyclic behaviour is modelled herein in a simplified way. A straight line is used for the unloading branch in tension. The same curve is considered for the reloading branch when there is no incursion in compression during a cycle. Based on experimental data from Reinhardt [33], the following criterion is proposed to account for the stiffness deterioration:

$\frac{E_{\text {new }}}{E_{0}}=\left(\frac{\varepsilon}{\varepsilon_{\mathrm{ct}}}\right)^{-1.05}$

where $E_{\text {new }}$ is defined in Fig. 10 .

\section{Transition curves}

A series of tests attempting to characterize the effect of damage in tension when the specimen is loaded in compression were developed by Ramtani et al. [38]. These test results have shown that completely closing the cracks requires a certain amount of compression. Once the crack is closed, the stiffness of the concrete is not affected by accumulated damage in tension.

The transition curve from tension to compression once the damage in tension is produced, closing the cracked zones, is assumed to be linear which is in agreement with experimental results (Légeron et al. [39]). The crack closure mechanism is governed by the "crack closure stress" $\sigma_{f}$ (see Fig. 11) which is the stress at which the crack is supposed to be completely closed. It has been observed that the crack closure stress is strongly affected by the concrete strength and placement methods (crack roughness). For monolithic structures with no previous damage in compression, $\sigma_{f}$ is in the range of the tensile strength (Légeron et al. [39]) and can be taken as

$\sigma_{f}=\sigma_{f}^{0}=-\frac{f_{c}^{\prime}}{10}$.
In the case of concrete with dry joints, $\sigma_{f}$ can be significantly lower.

The increasing of compression damage may produce a decrease in the magnitude of this variable (Mazars et al. [40]). A simple linear variation of $\sigma_{f}$ with the compression damage is considered herein as follows:

$\sigma_{f}=\left(1-\delta^{-}\right) \sigma_{f}^{0}$

where $\sigma_{f}^{0}$ is the initial crack closure stress (considered as input data by the user).

\section{Model verification. Comparison with test results}

Several uniaxial cyclic test results have been compared with predictions obtained by means of the model presented. These tests cover several concrete strengths and a variety of cyclic histories, including both cyclic compression and cyclic tension. In the case of cyclic compression, results from works performed by Okamoto et al. [14] and Tanigawa et al. [15] have been considered. In the case of cyclic tension and cyclic tension with small incursions in compression, the model is compared with test results from Reinhardt [33]. In all cases, the present model shows satisfactory agreement with the experimental results.

In Figs. 12-14, experimental tests carried out by Okamoto et al. [14] and Tanigawa et al. [15] are reproduced and compared with the model results and with those provided by Chang and Mander [7] and Yankelevsky and Reinhardt [4]. The mechanical characteristics considered for the model are summarized in Table 1.

In all cases the strains where the unloading curves start in the experimental results have been considered as the reverse points for the model.

Table 2 summarizes the dissipated energy obtained with the proposed model and is compared against experimental results and numerical results obtained by Chang and Mander [7] and Yankelevsky and Reinhardt [4].

In Figs. 15-17 three of the experimental tests performed by Reinhardt [33] are reproduced. The average compressive strength of the concrete specimens measured in $150 \mathrm{~mm}$ cubes was $f_{c}=47.1 \mathrm{MPa}$ (corresponding to a compressive strength measured in standard cylinders of $f_{c}^{\prime}=40.0 \mathrm{MPa}$ ) with a standard deviation of $s=2.83 \mathrm{MPa}$ and the tensile strength was $f_{\mathrm{ct}}=3.20 \mathrm{MPa}$ with a standard deviation of $s=0.30 \mathrm{MPa}$. The original curves were presented in the stress-displacement plane. To transform these curves to the stress-strain plane, the displacement data have been modified by considering the gauge length of the extensometers $(35 \mathrm{~mm})$. The average fracture energy reported by the authors was $G_{f}=$ $135 \mathrm{~N} / \mathrm{m}$. The model results have been obtained considering the same concrete characteristics of the experimental test. The characteristic length $l^{*}$ has been considered equal to $35 \mathrm{~mm}$. Concrete specimens were submitted to cyclic tension with different lower stress values.

In the first case (Fig. 15) the lower stress considered is 5\% of the tensile strength. In this case, the unloading and the reloading curves in the model coincide and there is no energy dissipation during a cycle. However, in the experimental results it can be 
ARTCLE IN PRESS

J.F. Sima et al. / Engineering Structures $x x(x x x x) x x x-x x x$

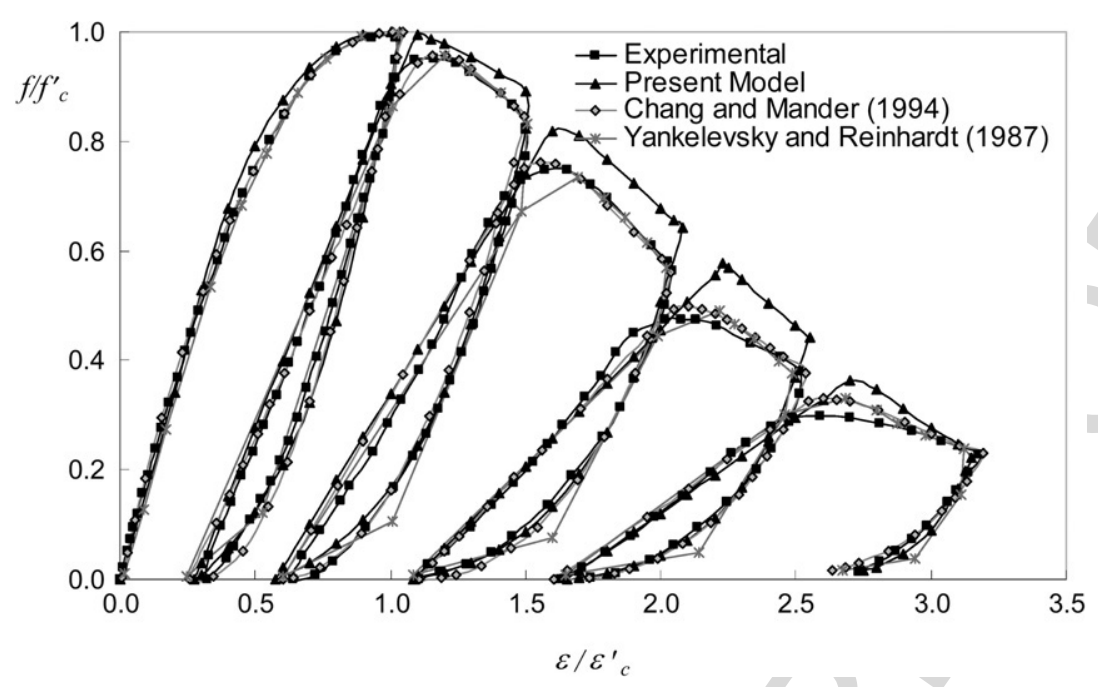

Fig. 12. Cyclic compression test by Okamoto et al. [14] $\left(f_{c}^{\prime}=30.0 \mathrm{MPa}\right)$.

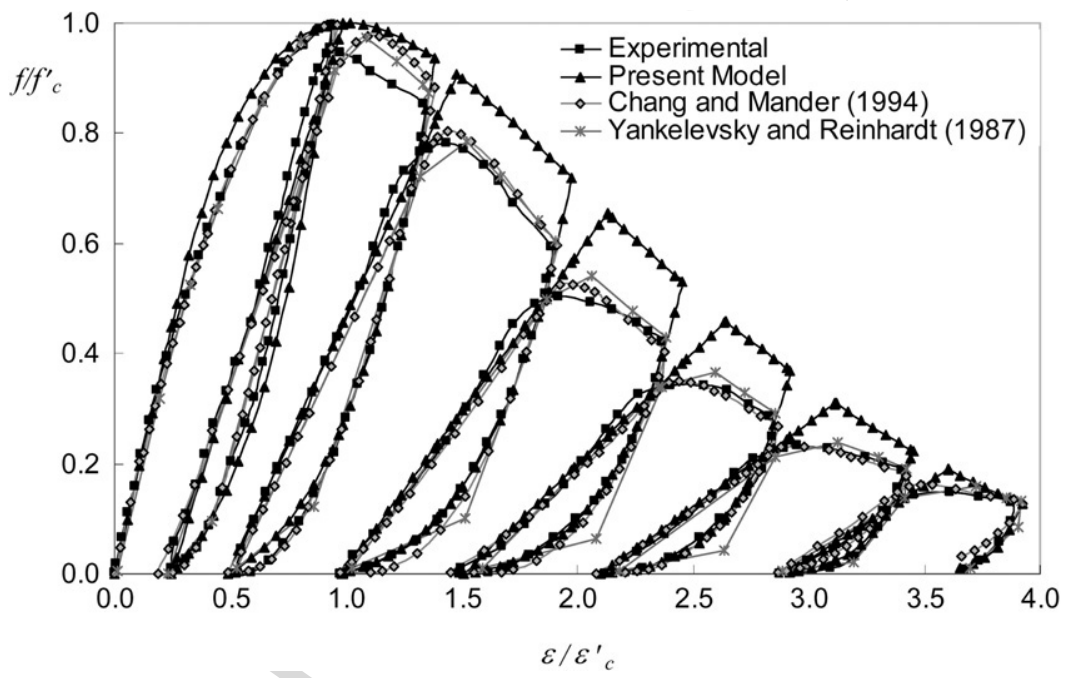

Fig. 13. Cyclic compression test by Okamoto et al. [14] $\left(f_{c}^{\prime}=40.0 \mathrm{MPa}\right)$.

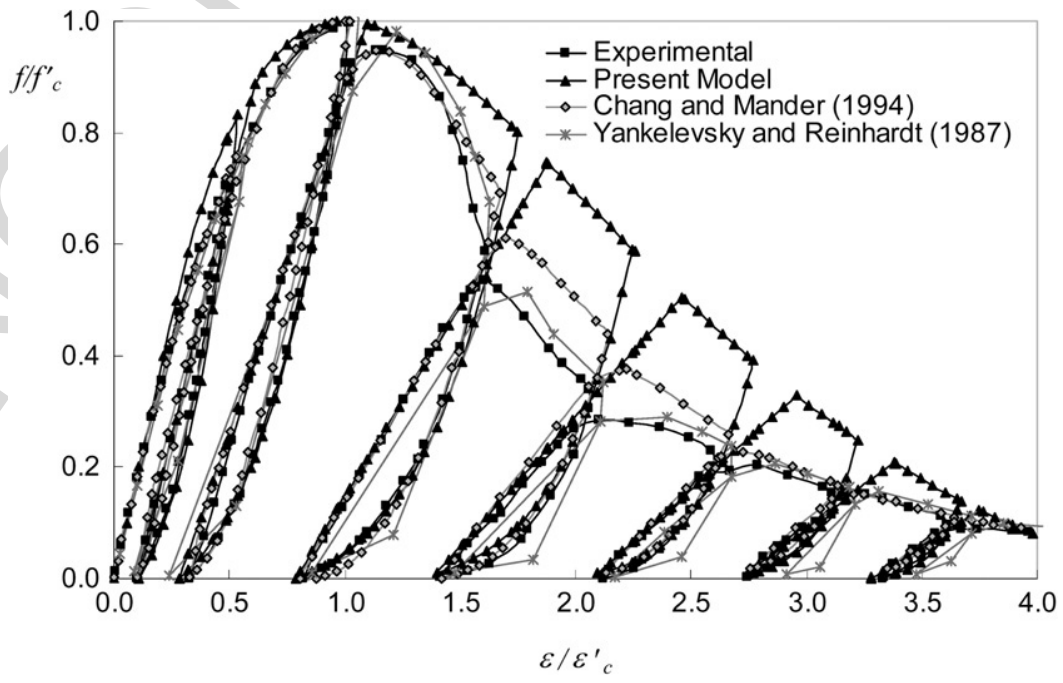

Fig. 14. Cyclic compression test by Tanigawa et al. [15] ( $\left.f_{c}^{\prime}=40.0 \mathrm{MPa}\right)$. 


\section{ARTICLE IN PRESS}

Table 1

Input data used for the compressive verification examples

\begin{tabular}{|c|c|c|c|c|c|c|}
\hline & $\varepsilon_{0}$ & $f_{c}^{\prime}$ & $\varepsilon_{c}^{\prime}$ & $E_{0}$ & $\varepsilon_{\mathrm{op}}$ & $f_{\mathrm{op}}$ \\
\hline Okamoto et al. (1976) — Fig. 12 & 0.0004 & 30.0 & 0.0020 & 25500 & 0.0070 & 4.0 \\
\hline Okamoto et al. (1976) — Fig. 13 & 0.0004 & 40.0 & 0.0019 & 39000 & 0.0072 & 4.0 \\
\hline Tanigawa (1979) — Fig. 14 & 0.0004 & 40.0 & 0.0020 & 40000 & 0.0074 & 3.3 \\
\hline
\end{tabular}

Table 2

Dissipated energy calculated for the compressive verification examples

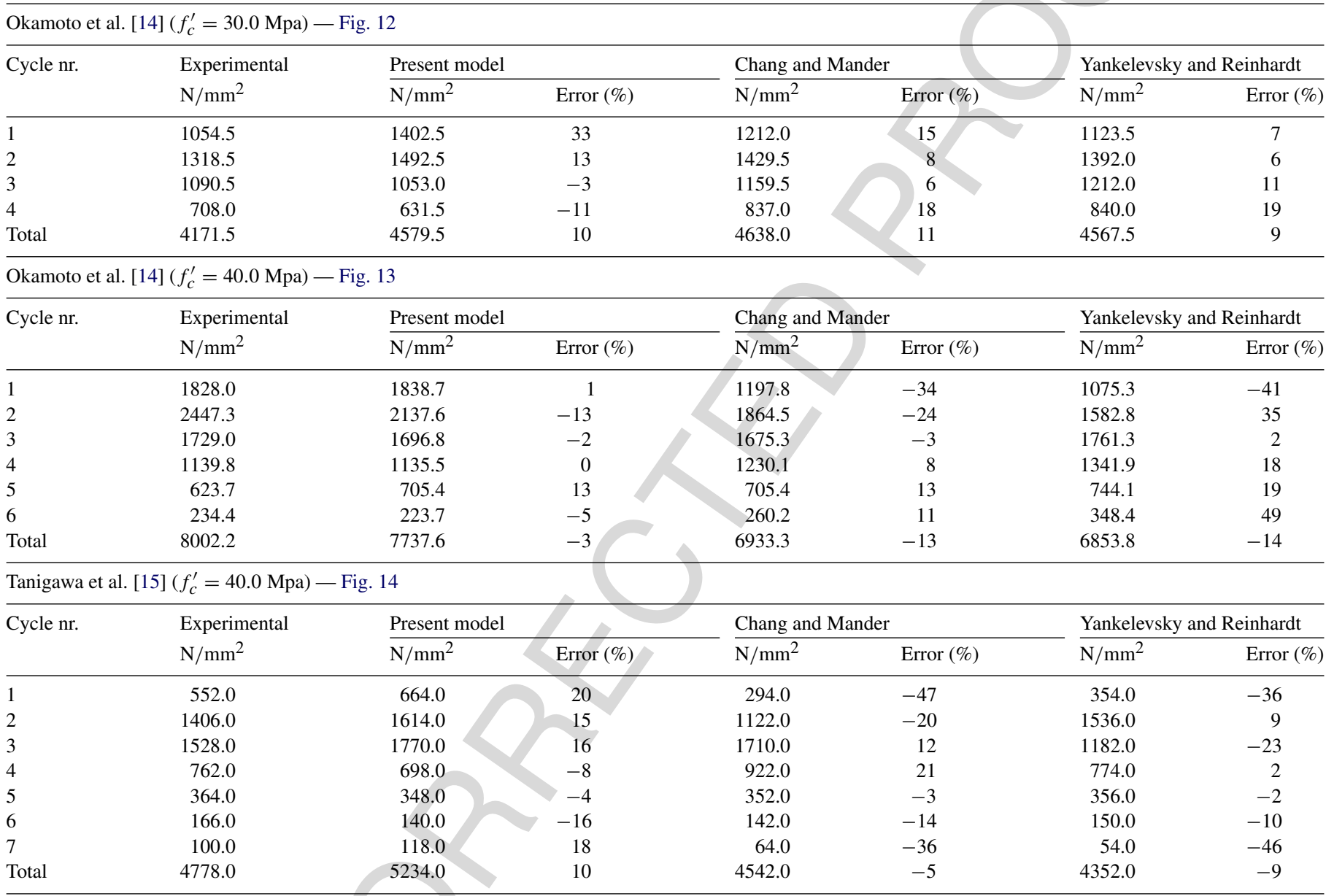

observed that the amount of energy dissipated in a cycle is really small. Based on these observations it can be concluded that the present model for unloading-reloading in tension is a satisfactory approximation of the real behaviour.

In the second case (Fig. 16) the lower stress considered is compressive and amounts to $15 \%$ of the tensile strength. In the experimental curve, the unloading and the reloading path of one cycle are significantly different, exhibiting a large hysteresis loop. This feature can be accurately simulated with the model by considering an adequate crack closure stress. A value $\sigma_{f}^{0}$ of $0.25 f_{\text {ct }}$ has been considered in this case.

In Fig. 17, experimental results of a test with large incursions in compression are presented. The lower stress considered is equal to the tensile strength. The loops produced in this case are still larger and the proposed model seems to be a satisfactory approximation.

\section{Concluding remarks}

A model for the simulation of the response of concrete subjected to cyclic loadings in both compression and tension has been presented. The model can reproduce the complex behaviour of concrete under any history of uniaxial cyclic loading. Particular emphasis has been paid to the simulation of the strength and stiffness degradation produced by the load cycling. Two independent damage parameters, one for damage in compression and the other for damage in tension, have been introduced to model the deterioration of concrete under increasing loads. A model for the loops due to cyclic compressive loadings has been proposed by considering its dependency with the damage accumulation in the concrete. Models for cyclic tension as well as crack opening and closing have been also proposed. 


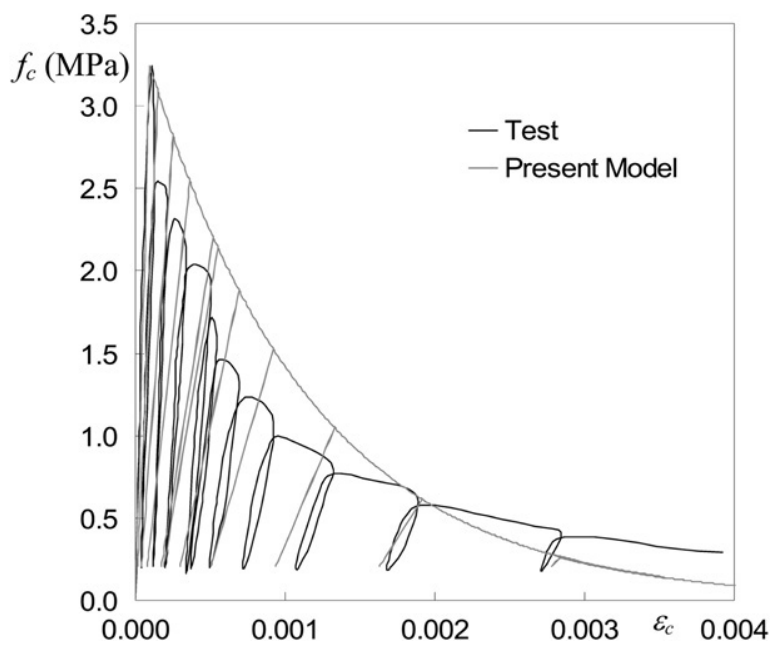

Fig. 15. Cyclic tension test by Reinhardt (1984).

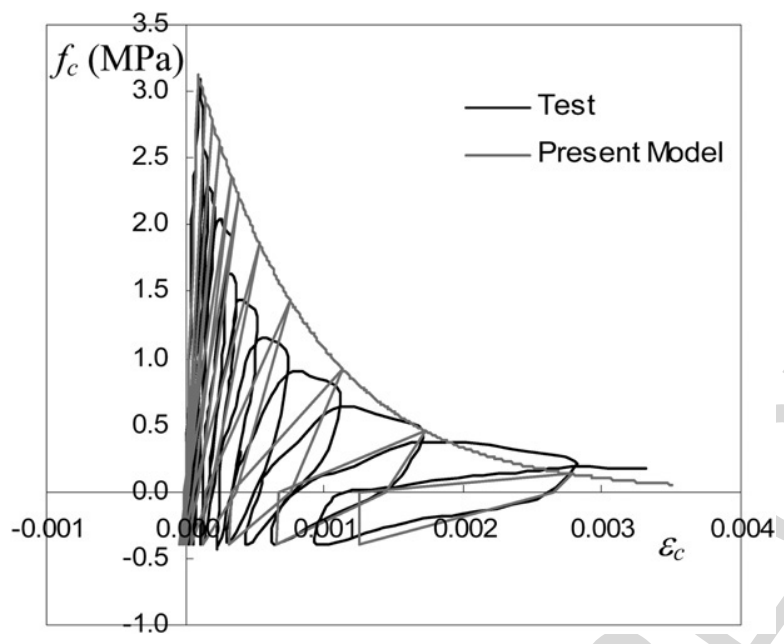

Fig. 16. Cyclic tension test with small incursions in compression by Reinhardt (1984).

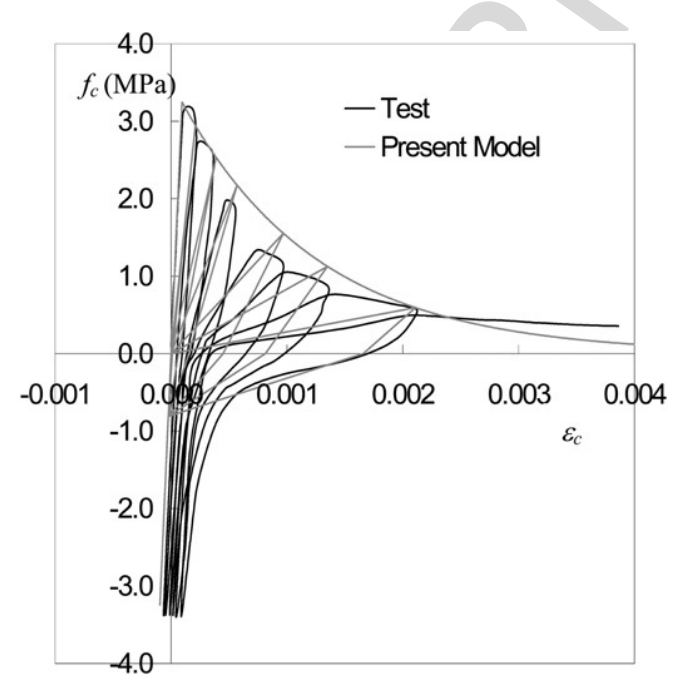

Fig. 17. Cyclic tension test with high incursions in compression by Reinhardt (1984).

A remarkable feature of the model lays in the fact that all the 2 monotonic compression and tension tests. The model has been validated by comparing the results with a series of tests developed by others authors. In all cases, the proposed model shows satisfactory agreement with the experimental results.

\section{Acknowledgements}

The studies presented here were developed within the research project ARQ2002-04659 funded by DGE of the Spanish Ministry of Science and Technology, whose assistance is gratefully acknowledged. The first author expresses his gratitude to the Education and Science Ministry of the Spanish Government for the financial support by means of a Grant for the Formation of University Teachers.

\section{References}

[1] Sinha BP, Gerstle KH, Tulin LG. Stress-strain relations for concrete under cyclic loading. J ACI 1964;61(2):195-211.

[2] Comite Euro-International du Beton. R.C. Elements under cyclic loadingState of the Art Report. London: Thomas Telford; 1996.

[3] Karsan ID, Jirsa JO. Behavior of concrete under compressive loadings. J Struct Div ASCE 1969;95(ST12):2543-63.

[4] Yankelevsky DZ, Reinhardt HW. Model for cyclic compressive behaviour of concrete. J Struct Engng ASCE 1987;113(2):228-40.

[5] Mander JB, Priestley MJN, Park R. Theoretical stress-strain model for confined concrete. J Struct Engng 1988;114(8):1804-26.

[6] Bahn BY, Hsu CT. Stress-strain behavior of concrete under cyclic loading. ACI Mat J 1998;95(2):178-93.

[7] Chang GA, Mander JB. Seismic energy based fatigue damage analysis of bridge columns: Part I-evaluation of seismic capacity. Technical report NCEER-94-0006. Buffalo (NY): State University of New York at Buffalo; 1994.

[8] Mansour M, Hsu TTC. Behavior of reinforced concrete elements under cyclic shear II: Theoretical model. J Struct Engng ASCE 2005;131(1): 54-65.

[9] Palermo D, Vecchio J. Compression field modeling of reinforced concrete subjected to reversed loading: Formulation. ACI Struct J 2003;100(5): 616-25.

[10] Popovics S. A review of stress-strain relationships for concrete. J ACI 1973;67(3):243-8

[11] Martinez-Rueda E, Elnashai AS. Confined concrete model under cyclic load. Mat Struct 1997;30:139-47.

[12] Ramberg WA, Osgood WR. Description of stress-strain curves by three parameters. Technical note no. 902. National Advisory Committee for Aeronautics. 1943.

[13] Spooner DC, Dougill JW. A quantitative assessment of damage sustained in concrete during compressive loading. Mag Concr Res 1975;27(92): 151-60.

[14] Okamoto S, Shiomi S, Yamabe K. Earthquake resistance of prestressed concrete structures. Proc Annual Convention AIJ 1976;1251-2.

[15] Tanigawa Y, Uchida Y. Hysteretic characteristics of concrete in the domain of high compressive strain. Proc Annual Convention AIJ 1979; 449-50.

[16] Vecchio FJ, Collins MP. The modified compression field theory for reinforced concrete elements subjected to shear. ACI J 1986;83(2): 219-31.

[17] Hsu TTC, Zhu RRH. Softened membrane model for reinforced concrete elements in shear. ACI Struct J 2002;99(4):460-9.

[18] Sakai J, Kawashima K. Unloading and reloading stress-strain model for confined concrete. J Struct Engng ASCE 2006;132(1):112-22.

[19] Molins C, Roca P. Capacity of masonry arches and spatial frames. J Struct Engng ASCE 1998;124(6):653-63.

[20] Hognestad E, Hanson NW, McHenry D. Concrete stress distribution in ultimate strength design. J ACI 1955;27(4):455-79. 
[21] Tsai WT. Uniaxial compression stress-strain relations of concrete. J Struct Engng 1988;114(9):2133-6.

[22] Mazars J, Pijaudier-Cabot G. Continuum damage theory. Application to concrete. J Engng Mech ASCE 1989;115(2):345-65.

[23] Faria R, Oliver J, Cervera M. A strain-based plastic viscous-damage model for massive concrete structures. Int J Solids Struct 1998;35(14): 1533-58.

[24] Saetta A, Scotta R, Vitaliani R. Coupled environmental-mechanical damage model of RC structures. J Engng Mech ASCE 1999;125(8): 930-40.

[25] Saetta A, Scotta R, Vitaliani R. Analysis of masonry vaulted structures by using 3-D damage model. In: Proc European congress on computational methods in applied sciences and engineering. 2000.

[26] Berto L, Saetta A, Scotta R, Vitaliani R. An orthotropic damage model for masonry structures. Int J Numer Meth Engng 2000;55:127-57.

[27] Buyukozturk O, Tseng TM. Concrete in biaxial cyclic compression. J Struct Engng 1984;110(3):461-76.

[28] Bažant ZP, Oh BH. Crack band theory for fracture of concrete. Mat \& Struct RILEM 1983;16(93):155-77.

[29] Rots JG, Nauta P, Kusters GM, Blaauwendraad J. Smeared crack approach and fracture localisation in concrete. Heron 1985;30.

[30] Gopalaratman VS, Shah SP. Softening response of plain concrete in direct tension. ACI J 1985;82(3):310-23.

[31] Lin CS, Scordelis A. Non linear analysis of RC shells of general forms.
J Struct Engng ASCE 1975;101(ST3):523-38.

[32] Cornelissen HAW, Hordijk DA, Reinhardt HW. Experiments and theory for the application of fracture mechanics to normal and lightweight concrete. In: Wittman FH, editor. Proc. int. conf. on fracture mechanics of concrete. Amsterdam (The Netherlands): Elsevier; 1985.

[33] Reinhardt HW. Fracture mechanics of an elastic softening material like concrete. Heron 1984;29.

[34] Reinhardt HW, Cornelissen HAW, Hordijk DA. Tensile test and failure analysis of concrete. J Struct Engng 1986;112(11):2462-77.

[35] Okamura H, Maekawa K. Non linear analysis and constitutive models of reinforced concrete. Japan: Giho-do Press, University of Tokyo; 1991.

[36] Hordijk DA. Local approach to fatigue of concrete. The Delft University of Technology. 1991.

[37] Oliver J. A consistent characteristic length for smeared cracking models. Int J Numer Meth Engng 1989;28:461-74.

[38] Ramtani S, Berthaud Y, Mazars J. Orthotropic behavior of concrete with directional aspects: Modeling and experiments. Nuclear Engng Design 1992;133:97-111.

[39] Légeron F, Paultre P, Mazars J. Damage mechanics of nonlinear seismic behavior of concrete structures. J Struct Engng 2005;131(6):946-55.

[40] Mazars J, Ragueneau F, Casaux G, Colombo A, Kotronis P. Numerical modeling for earthquake engineering: The case of lightly RC structural walls. Int J Numer Anal Meth Geomech 2004;28:857-74. 